\title{
Motor neuron disease
}

\author{
P N Leigh, K Ray-Chaudhuri
}

For neurologists, the management of motor neuron disease (MND) involves prompt and accurate diagnosis; an understanding of natural history, prognosis, and of the physical and psychological consequences of the disease for the individual and for carers; familiarity with the techniques, philosophies, and ethical aspects of symptomatic treatment, rehabilitation medicine and palliative care; and awareness of the new opportunities for research into the causes and treatment of MND and other motor neuron disorders. Because MND is a relatively rare condition for most health workers, the neurologist can make an important contribution to effective multidisciplinary management. Underprovision of neurology services militates against this in the United Kingdom. Nevertheless, an argument can be made that MND be treated as a "special case" and that health districts should develop appropriate models of interdisciplinary care, not necessarily led, but advised and supported by, local neurologists.

University
Department of
Neurology, Institute of
Psychiatry and King's
College School of
Medicine and
Dentistry, De
Crespigny Park,
London SE5 8AF, UK
P N Leigh
K Ray-Chaudhuri
Correspondence to:
Professor P N Leigh

Definitions and terminology

MND is a progressive disorder in which degeneration of upper and lower motor neurons leads to progressive weakness of bulbar, limb, thoracic, and abdominal muscles with relative sparing of oculomotor muscles and sphincter function. Death from ventilatory failure usually follows within five years of onset. Most cases are sporadic (90-95\%), whereas $5-10 \%$ are familial, ${ }^{12}$ usually with autosomal dominant transmission. Many other motor system and anterior horn cell disorders are recognised (table 1). An unusual form of MND occurs in the Western Pacific associated with parkinsonism and dementia. ${ }^{3}$

In the United Kingdom the term MND is used generically to include the complete spectrum of the disease, including Charcot-type amyotrophic lateral sclerosis (ALS) with typical upper and lower motor neuron involvement, progressive muscular atrophy with only lower motor neuron involvement, and progressive bulbar palsy with bulbar and pseudobulbar palsy. The relationship between primary lateral sclerosis, in which progressive upper motor neuron degeneration is not accompanied by anterior horn cell degeneration, and other forms of MND, remains uncertain. Most cases do not progress to typical MND. ${ }^{4}$

\section{Diagnostic criteria}

At a World Federation of Neurology consensus conference in 1990 at El Escorial, Spain, research diagnostic criteria for MND were suggested (table 2). ${ }^{5}$ These criteria are based on clinical evidence of a progressive disorder with the characteristic combination of upper and lower motor neuron involvement in the same body regions and with certain exclusion

Table 1 Some rare disorders showing features of anterior horn cell degeneration

\begin{tabular}{|c|c|c|}
\hline Disorder & Associated neurological features & Diagnostic pointers \\
\hline $\begin{array}{l}\text { X-linked recessive bulbar and spinal muscular } \\
\text { atrophy }\end{array}$ & Postural tremor; prominent facial fasciculations & $\begin{array}{l}\text { Male gender; gynaecomastia; diabetes; infertility } \\
\text { Absent SAPs; androgen receptor gene mutation }\end{array}$ \\
\hline $\begin{array}{l}\text { Hereditary spastic paraparesis with distal } \\
\text { amyotrophy }\end{array}$ & Pes cavus; vibration sense loss; dementia; dystonia & $\begin{array}{l}\text { Positive family history; early age at onset; slow } \\
\text { progression; ethnic origin (Amish; Tunisian; Lebanese) }\end{array}$ \\
\hline $\begin{array}{l}\text { Juvenile spinal muscular atrophy of the distal upper } \\
\text { extremity }\end{array}$ & $\begin{array}{l}\text { Exacerbation of weakness by cold; } \\
\text { minipolymyoclonus of fingers }\end{array}$ & $\begin{array}{l}\text { Young Japanese males; vasomotor disturbances; benign } \\
\text { course; structural abnormality of cervical cord }\end{array}$ \\
\hline "Madras" pattern motor neuron disease & $\begin{array}{l}\text { Sensorineural hearing loss; minipolymyoclonus } \\
\text { of fingers }\end{array}$ & Ethnic origin (southern Indian); young age at onset \\
\hline Western Pacific ALS & Parkinsonism; dementia & $\begin{array}{l}\text { Ethnic origin (Guam, Western New Guinea, Kii } \\
\text { peninsula of Japan) }\end{array}$ \\
\hline Adult GM2 gangliosidosis & $\begin{array}{l}\text { Intellectual impairment; psychiatric disturbances; } \\
\text { ataxia; stutter-dysarthria; pyramidal tract signs; } \\
\text { dystonia; dyskinesias; supranuclear ophthalmoplegia }\end{array}$ & $\begin{array}{l}\text { Ethnic origin (Ashkenazi Jews) } \\
\text { White cell/skin fibroblast hexosaminidase A } \\
\text { deficiency; EM of rectal biopsy }\end{array}$ \\
\hline Azorean disease (Machado-Joseph disease) & $\begin{array}{l}\text { Cerebellar syndrome; parkinsonism; supranuclear } \\
\text { ophthalmoplegia; pseudobulbar palsy; dystonia }\end{array}$ & $\begin{array}{l}\text { Ethnic origin (Portuguese; Azorean); family history; } \\
\text { diabetes }\end{array}$ \\
\hline Multiple system atrophy and OPCA & $\begin{array}{l}\text { Orthostatic hypotension; parkinsonism; cerebellar } \\
\text { ataxia; nystagmus; urinary incontinence; } \\
\text { impotence; dementia; involuntary movements; } \\
\text { dysphagia; supranuclear ophthalmoplegia }\end{array}$ & $\begin{array}{l}\text { Family history (some cases); infratentorial atrophy } \\
\text { on CT or MRI }\end{array}$ \\
\hline
\end{tabular}


Table 2 Diagnostic criteria for motor neuron disease (amyotrophic lateral sclerosis, $A L S$ )

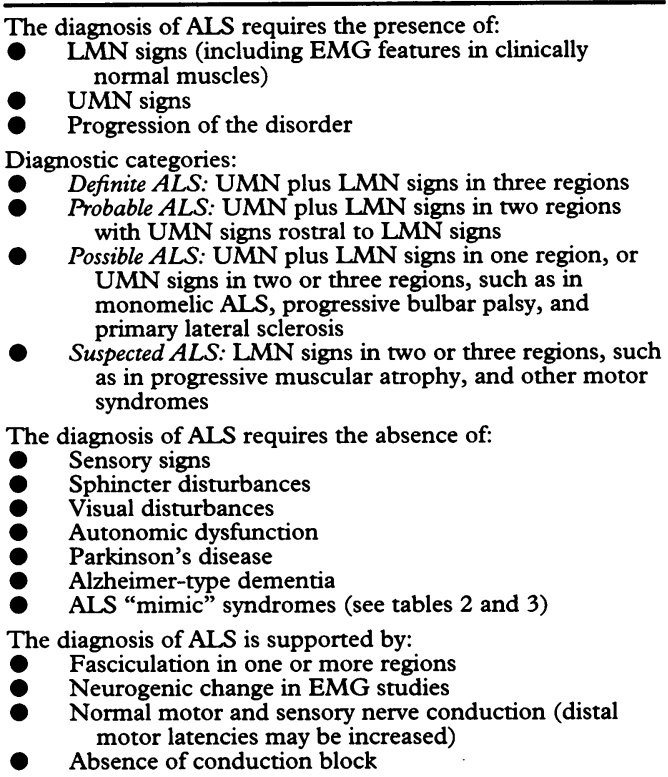

Regions are defined as follows: brainstem, brachial, thorax and trunk, crural. UMN = Upper motor neuron; LMN = lower motor neuron.

criteria. Validation of these criteria is needed, but the predictive power of the definite and probable categories is high, judged by neuropathological correlations ${ }^{6}$ and by experience in clinical trials that have used these categories as inclusion criteria. The diagnostic accuracy of the category of possible ALS remains to be defined by long term follow up and neuropathology. Although valuable as research criteria, the El Escorial criteria do not take account of the vagaries of clinical practice; patients with MND sometimes have bladder dysfunction, and dementia and parkinsonism are rare features of otherwise pathologically typical $\mathrm{MND}^{7-9}$ Other disorders, such as spondylotic myelopathy, often coexist with MND. Thus for clinical rather than research purposes the exclusion criteria should be interpreted flexibly and used to alert clinicians to rare and potentially treatable disorders.

These research diagnostic criteria have been applied to sporadic and familial forms of MND. ${ }^{5}$ The familial motor neuron disorders of adult onset are rare and only the milder forms of spinal muscular atrophy, Kennedy's disease, and autosomal dominant MND are seen regularly in adult neurological practice. Nevertheless these disorders offer new possibilities for understanding the mechanisms of motor neuron degeneration. ${ }^{1011}$ The diversity and genetic heterogeneity of motor neuron disorders are exemplified by the World Federation of Neurology classification which includes 28 autosomal dominant syndromes, 37 autosomal recessive syndromes and seven $\mathrm{X}$-linked syndromes, with an additional 16 different types of MND-dementiasyndrome. ${ }^{12}$

Clinical features and differential diagnosis SYMPTOMS AND SIGNS

In $75 \%$ of patients, the first symptoms are in the limbs; $25 \%$ present with bulbar symptoms. ${ }^{13-15}$ The earliest symptom is usually asymmetrical weakness of one extremity or, with bulbar onset disease, slurring of speech. The latter is often noted first by family or friends. Specific symptoms with limb onset disease depend on the area involved. In the arms, weakness may start around one shoulder, and sometimes is noticed after a minor local injury, or progresses after what has been considered to be a "frozen shoulder". Distal weakness is often manifest as increasing difficulty turning a key in a lock or car ignition, unscrewing bottle tops, holding a pen, or gripping objects. Involvement of arms first occurs in about $35 \%$ of cases. The disease begins in the lumbosacral region of the spinal cord in about $40 \%$ of patients. Such patients begin to trip or stumble due to a unilateral foot drop, or may have difficulty rising from a chair if weakness starts proximally. Rarely patients note stiffness and flexor spasms in the legs, resulting from spasticity. Fatigue is not a particularly prominent early symptom, but muscle cramps are common, mostly in the legs where proximal and distal muscles are affected. Fasciculations may attract attention, and cramps and fasciculations sometimes precede weakness and wasting by several months. Sensory symptoms, usually variable distal paraesthesiae or numbness, are present in about $10 \%$ of patients and pain may be a prominent symptom in up to $50 \%$ of MND patients with advanced disease.

With time, weakness progresses but fasciculations often become less obvious. Almost all patients with limb onset eventually develop bulbar symptoms and, conversely, patients with bulbar onset disease ultimately develop symptoms in the limbs. Orthopnoea, due to diaphragmatic weakness, is common. In bulbar onset disease, dysarthria progresses until speech is incomprehensible; many patients become anarthric. Dysphagia usually begins as difficulty clearing a bolus of solids, proceeds to difficulty even with liquified foods and fluids, and eventually becomes total. Drooling of saliva may be a constant irritation. These symptoms, with limb weakness, ultimately render such people dependent on others for every form of comfort, sustenance, and care. Fortunately, pressure sores are rare, and urinary and faecal incontinence seldom occur.

Although ventilatory muscle weakness occurs in almost all patients and, with or without pneumonia, is usually responsible for death, dyspnoea is not always a prominent symptom. It may, however, be present early in the course of the disease when limb weakness is negligible and rarely patients present with dyspnoea or even ventilatory failure.

The physical signs of MND stem from upper motor neuron involvement causing weakness, spasticity, hyperreflexia, and Babinski's sign (although the latter is present only in $50 \%)^{15}$ and from lower motor neuron involvement causing weakness, muscular atrophy, and fasciculation. Dysphagia and dysarthria may be due to upper or lower 
motor neuron involvement or, in most cases, combined lesions. Emotional lability is usually associated with pseudobulbar palsy and is a sign of upper motor involvement. Both upper and lower motor neuron signs are often evident at presentation in $65 \%$ of patients. ${ }^{14} 15$ Fasciculation can occur in the absence of other lower motor neuron signs. Ten per cent of patients present with lower motor neuron features only, but some develop upper motor neuron signs and only about $5 \%$ show the phenotype of progressive muscular atrophy throughout the course of the disease. ${ }^{15}$

Objective sensory signs exclude a diagnosis of MND unless there is a clear alternative explanation, such as carpal tunnel syndrome. Detailed testing with measurement of, for example, thermal threshold, may show impaired sensation, and sural nerve biopsies have revealed evidence of axonal degeneration in some cases of MND. ${ }^{16}{ }^{17}$ In endstage $M N D$, there may be multisystem involvement with degeneration of the spinocerebellar tracts, posterior columns, and brainstem reticular formation, although clinically this is of little importance. ${ }^{18}$

Dementia, which may be associated with parkinsonism, is seen in less than $5 \%$ of patients, ${ }^{7-9}$ but subtle cognitive changes indicative of frontal and temporal lobe dysfunction can be detected in $25-50 \%$ of patients, and PET activation studies show markedly impaired responses in the medial frontal region and anterior thalamus in these patients. ${ }^{19}$ Dementia associated with MND is usually of frontal lobe rather than Alzheimer type, and typically patients present with changes in conduct and character, although memory impairment may predominate. A family history of dementia with or without MND, suggestive of autosomal dominant transmission, is present in some cases. ${ }^{70}$

The Western Pacific ALS-parkinsonismdementia complex (PDC) occurs on the island of Guam, the Kii peninsula in Japan and in parts of New Guinea. In this syndrome features of ALS coexist with extrapyramidal signs and dementia. The spinal cord pathology is that of typical MND, but in addition there is neurofibrillary degeneration in cerebral cortex and brainstem, and, to a lesser extent, in the spinal cord. ${ }^{21}$ Current indications are that ALS on Guam is declining in frequency.

Although in the differential diagnosis of MND a large number of disorders must be considered (tables 1 and 3 ), in practice the diagnosis is usually straightforward by the time the patient is referred to a neurologist.

Because the early symptoms may be illdefined, or may be mistaken for localised lesions, it is common for patients to be referred first to rheumatology, orthopaedic, ENT, or psychiatric departments. In the very elderly, the diagnosis may be especially difficult in the early stages. In 62 consecutive patients referred with a diagnosis of MND to a research clinic for clinical trials we found six patients who were judged not to have MND including two patients with Kennedy's
Table 3 Conditions that should always be considered in the differential diagnosis of $M N D$

- Cervical spondylotic myelopathy and other cervical and

lumbosacral radiculopathies
- Disorders associated with autoimmune processes:

(a) Dysimmune lower motor neuron syndromes

(G) $\left(\mathrm{GM}_{1}, \mathbf{G D}_{1 \mathrm{~b}}\right.$ and asialo-GM $\mathrm{M}_{1}$ antibodies)

(b) Monoclonal gammopathy with conduction block and motor neuropathy

(c) Lymphoma

(d) Paraneoplastic syndrome (encephalomyelitis with anterior horn cell involvement)

Thyrotoxicosis

Hyperparathyroidism

Diabetic "amyotrophy"

Radiation-induced neurogenic disorders

Post-poliomyelitis progressive muscular atrophy

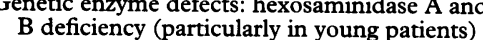

Exogenous toxin disorders (lead, mercury, manganese

toxicity)
"Prion" disorders (amyotrophic forms of Creutzfeldt-

Jakob disease)

Certain myopathies, such as inclusion body myositis

syndrome, one with cerebrovascular disease and cervical spondylosis, two with motor neuronopathy and multifocal conduction block, and one with inclusion body myositis. It is difficult to know what the diagnostic error rate would be in a less selected group of patients.

\section{Investigations}

The purpose of laboratory investigations is to exclude other diagnoses, and to support the diagnosis of MND. At present there are no specific biochemical or pathological markers of the disease.

\section{ESSENTIAL INVESTIGATIONS}

Erythrocyte sedimentation rate, haematological and biochemical screen, chest radiograph, and ECG should be undertaken in all patients with suspected MND. It is advisable to request antinuclear, thyroid function tests, vitamin B12 and folate levels, VDRL tests and protein electrophoresis. These tests are done mainly to exclude coincidental disease that may influence management, but also to exclude thyroid and parathyroid disorders and autoimmune disorders that may be associated with motor neuronopathy or atypical spinal cord syndromes. Serum creatinine kinase levels may be elevated, particularly in those with predominantly lower motor neuron involvement and slow progression, but also in Kennedy's disease. This last can be excluded by testing for the androgen receptor gene mutation in all male patients where there is a suggestion of X-linked inheritance, or lacking a clear family history, where the clinical picture raises the possibility. ${ }^{1022}$ The patient and family should receive appropriate counselling before testing. Key features of Kennedy's disease are early onset (which can be in the teens, although it may be as late as the sixth or seventh decades), slow progression of mainly proximal lower motor neuron weakness associated with facial and tongue weakness and fasciculation, gynaecomastia, and tremor of the hands. Depressed reflexes and reduced sensory nerve action potentials may also be potential clues to Kennedy's syndrome. 
Electromyography and nerve conduction studies are important aids to the diagnosis of MND, and can exclude other neuromuscular disorders such as myopathy and motor neuronopathy. In essence, EMG furnishes evidence of widespread anterior horn cell damage that cannot be explained on the basis of a localised disease process. Thus it is necessary to show denervation and reinnervation outside the distribution of a single peripheral nerve or nerve root. Although the examination depends largely on analysis of potentials detected by concentric needle electrodes, recording of fasciculation potentials using surface electrodes is a useful non-invasive adjunct, allowing many muscles to be examined. Table 4 summarises the criteria used to support a diagnosis of MND. ${ }^{23}$ These criteria cannot always be satisfied in early stages of MND. Fibrillation potentials are often absent, particularly in patients with slower disease progression. Unstable motor units and increased jitter are an essential part of electrophysiological diagnosis, but are not specific for MND. Likewise, reduced recruitment and large motor unit potentials are nonspecific, but in MND larger motor unit amplitudes are seen in relation to disease duration than in any other condition. The balance between the features of rapidly advancing denervation with little reinnervation (frequent fibrillations and fasciculations, highly unstable complex potentials of only moderately increased amplitude) and those of more slowly progressive disease (scanty fibrillations, with complex very high amplitude but relatively stable motor units) differs from case to case and even between different muscles in one patient. Fasciculations in MND are of a lower frequency $(0.3 \mathrm{~Hz})$ than in the benign fasciculation syndrome $(1.25 \mathrm{~Hz})$. In the latter, fasciculations are not associated with abnormal voluntary motor unit potentials.

Several other points are worth considering. Firstly, motor conduction velocity is seldom low enough to suggest demyelination, although conduction studies may be unreliable where the compound muscle action potential amplitudes are very low. ${ }^{24}$ Secondly, a mild reduction in sural nerve action potential amplitude does not exclude the diagnosis of MND. Thirdly, low amplitude of compound muscle action potentials and a decremental response to repetitive nerve stimulation may indicate rapid progression. ${ }^{25}$ Finally, conduction block is not a feature of

Table 4 EMG criteria for diagnosis of motor neuron disease (from ref ${ }^{23}$, with permission)

\footnotetext{
- Fibrillation and fasciculation in muscles of the lower and the upper extremities, or in the extremities and the head

the head
Reduction in number and increase in amplitude and duration of motor unit action potentials

- Normal electrical excitability of remaining fibres of Normal electrical excitability of remaining fibres of
motor nerves, and motor fibre conduction velocity motor nerves, and motor fibre conduction velocity
within the normal range in nerves of relatively within the normal range in nerves of relatively
unaffected muscles and not less than $70 \%$ of the unaffected muscles and not less than $70 \%$ of the
average normal value according to age in nerves of average normal value according
more severely affected muscles

more severely affected muscles
- Normal excitability and conduction velocity of sensory nerve fibres even in severely affected extremities
}

typical MND and, when present, raises the possibility of multifocal motor neuropathy or other demyelinating neuropathy. On the other hand, conduction block is not by itself diagnostic of multifocal motor neuronopathy, particularly if it is only present at common sites of nerve compression. Motor conduction block should therefore be sought in nerves not usually liable to pressure palsies. Conduction block implies a greater than $50 \%$ reduction in the compound muscle action potential amplitude and the negative peak area following proximal versus distal nerve stimulation with less than $15 \%$ change in the duration of the negative peak.

Single fibre EMG, macro EMG and central motor conduction using magnetic stimulation are useful techniques for research into motor system and motor unit physiology. Abnormal jitter and blocking of neuromuscular transmission and increased fibre density detected by single fibre EMG reflect early reinnervation and collateral sprouting and may provide evidence of anterior horn cell damage in otherwise normal muscles. These techniques are not mandatory for clinical diagnosis and seldom add critical information beyond what can be obtained with the more conventional approaches described above.

\section{DESIRABLE INVESTIGATIONS}

Many neurologists would now regard MRI as mandatory in patients with possible MND; that is, where there is any possibility that the signs might be caused by a single lesion. Imaging may be focused on the head, neck, or thoracolumbar region, depending on the presenting symptoms and signs. MRI not only helps to exclude common disorders such as spondylotic myelopathy or neoplasm, but may reveal extensive corticospinal tract involvement with high intensity white matter lesions in the cortex, internal capsule, brainstem, and spinal cord. ${ }^{26}{ }^{27}$ Bilateral T2 shortening in the precentral cortex and hyperintensity of the spinal cord corticospinal tracts at nuclear magnetic resonance imaging have been reported in MND. ${ }^{28}$

Lumbar puncture with analysis of CSF should be undertaken in atypical cases but, in most cases, CSF analysis adds little and in many centres it is not done routinely. A high protein level (over $0.75 \mathrm{~g} / \mathrm{l}$ ), the presence of oligoclonal bands, or increased numbers of leucocytes, indicate other causes. In a group of nine patients in whom MND was associated with lymphoma, most had raised CSF protein, and oligoclonal bands were present in three. ${ }^{29}$

\section{OCCASIONAL INVESTIGATIONS}

A variety of conditions may mimic the clinical features of MND (tables 2 and 3), and occasionally the following investigations may be relevant: a search for antibodies against gangliosides ${ }^{30}{ }^{31}$ and, occasionally, anti-Hu antibodies $^{32}$; leucocyte or fibroblast hexosaminidase A and B activity; HIV and HTLV1 assay; blood lead and 24-hour urinary lead excretion. 
SPECT studies may show reduced cerebral blood flow in the frontal regions in patients with MND and dementia ${ }^{9}$ but this investigation is not helpful in most cases of MND.

Familial MND cases may now be screened for point mutations in the $\mathrm{Cu} / \mathrm{Zn}$ superoxide dismutase (SOD 1) gene on the long arm of chromosome 21 (21q22.1-22.2), but this should not be undertaken without proper counselling. ${ }^{11}$

\section{Epidemiology, risk factors, and prevention}

The incidence of MND is 1-2 per 100000 and the prevalence is 4-6 per 100000 in most parts of the world, except the Western Pacific foci. ${ }^{33} 34$ In Guam, the incidence of MND has fallen from 87:100 000 in 1962 to 5:100 000 in $1985 . .^{21}$ The incidence of MND elsewhere may be rising, although this could be due to improved ascertainment and demographic factors. ${ }^{35-37}$ The average general practitioner might expect to see a new case of MND only once every 25 years. Most surveys have found that the incidence of MND increases with age to a peak between 60 and 70 years. ${ }^{34} 36$ In almost all studies, men are more commonly affected than women, with a ratio of around $1 \cdot 5: 1 .{ }^{34-36}$ In brief, proven risk factors for MND include increasing age, male sex, and residence for many years in certain parts of the Western Pacific.

As the cause of MND is unknown, and modifiable risk factors have yet to be defined with certainty, there are at present no known primary or secondary prevention options. Trauma of many types, exposure to a variety of toxins (cyanide, lead, aluminium) and farming, and particularly heavy manual activity are possible, but unproven, risk factors. ${ }^{34} 36$ In the small community of Two Rivers in Wisconsin, United States, a cluster of six cases occurring over a period of 7.5 years was detected..$^{38}$ Generally the evidence for clustering is weak. Physical trauma, freshly caught fish from Lake Michigan, and family history of cancer were implicated as risk factors in this group. Previous infection with polio virus is probably not a significant risk factor. ${ }^{39}$

In the Guam MND-PDC syndrome, consumption of a dietary excitotoxin, $\beta-N$ methylamino-L-alanine (L-BMAA), found in cycad flour obtained from false sago palm (Cycas circinalis), has been implicated as a causative factor. ${ }^{40}$ L-BMAA now seems an unlikely factor, however, as insufficient amounts exist in cooked food to be a neurotoxin. ${ }^{41}$

Mortality for MND has been reported to be different in various ethnic communities. Asian immigrants (Indian and Pakistani) to England have less than half the mortality from MND compared with the general population of England and Wales. Mortality from MND may also be low in white South Africans (particularly in the Afrikaans-speaking group) and in Mexican patients. ${ }^{42-44}$

\section{Prognosis}

KNOWN OUTCOMES

Median survival for all sporadic MND patients is about 3.5 years from onset of symptoms. ${ }^{15} 45$ In a recent, prospective study of 229 patients with MND, however, Chancellor et $a l^{46}$ reported that, overall, $50 \%$ survival from symptom onset was 2.5 years and five year survival was $28 \%{ }^{46}$ Benign MND or long duration MND is recognised, and comprises about $5 \%$ of all cases. ${ }^{15}$ Early onset (below 50 years) is associated with longer survival. It has been reported that $10-16 \%$ of patients with MND may live longer than 10 years, demonstrating a "resistance in MND" ${ }^{47}$ Tucker et $a l^{48}$ reported four patients with an MND-like syndrome who recovered completely 5-12 months after disease onset. ${ }^{48}$ Complete recovery in MND has not been confirmed in a follow up study of 708 cases. $^{15}$

Bulbar onset is associated with significantly reduced survival, median survival being about 22 years. It is the single most important indicator of poor prognosis. It is rare for people presenting with progressive bulbar palsy to survive beyond 5 years. ${ }^{15}$ Older age and female sex are adverse risk factors; progressive bulbar palsy occurs with greater frequency in women.

\section{Communication and counselling}

Increasingly, the neurologist is part of a multidisciplinary team, and a team approach is probably most satisfactory for coping with the changing needs of people with MND.

\section{TELLING THE DIAGNOSIS}

Once the diagnosis has been established by clinical examination and supported by the appropriate investigations, the patient and spouse or close carer should be informed of the diagnosis and should be allowed time to explore the implications. "Telling" should take place with privacy, and a provisional plan for early follow up and support should be agreed. Most people register only a fraction of the information imparted at such interviews, and leaflets can alarm more than reassure at this early stage. Our practice is to explain the diagnosis with a chosen carer (usually a spouse) and with our care team coordinator present. Follow up is then arranged within two weeks. Close liaison with the general practitioner is important. The patient is given the local contact telephone numbers for the MND care team and for the MND Association, who fund regional care advisers to provide advice and practical support. With the permission of the patient and family, we inform the RCA about the newly diagnosed patient.

In our experience, support of the local and national MND Association forms a key part of an effective care strategy. Although a few individuals prefer not to have contact with the MND Association, most patients benefit from early referral. 
SUPPORT AND EXTERNAL AGENCIES: THE ROLE OF THE KEYWORKER

Models of care through team work will differ according to local circumstances, but the concept that each patient should be allocated a keyworker has much to recommend it. A keyworker is likely to be a health professional who agrees to coordinate the activities of the many services that must work efficiently together to support MND patients and their families. The keyworker might be the general practitioner, community occupational or speech therapist, practice nurse or the hospital based team coordinator.

\section{FOLLOW UP AND SUPPORT}

Patients may know little about MND or may have preconceived and erroneous ideas. They can be reassured that generally the intellect, sexual and sphincter functions will remain intact. The patient should be encouraged to lead a normal life for as long as possible, but practical difficulties should be foreseen so that appropriate action can be taken to prevent crises. Patients may benefit from a visit to a disabled living centre or to a specialised neurological rehabilitation centre. Referral to a "mobility centre" for advice on driving can be helpful. This theme of coordinating care to minimise delays in the provision of aids and appliances and other forms of support is fundamental to the good management of MND. Advice about employment, finance, and family matters should be available from the team and from expert counsellors. People with MND often feel abandoned by doctors, but regular outpatient attendances may be of little value unless there is a positive care plan and both the patient and doctor have a clear idea of what clinic visits can achieve. Continued support from a keyworker, close links with the general practitioner, a telephone hotline for advice and crisis situations, hospital admission for respite care or crises, and access to hospice care are all important components of the management of MND. Depression is common, as are frustration, anger, and irritability, the last most often directed against spouse or carer, but also against health professionals. ${ }^{49}$

\section{Treatment strategies}

Table 5 summarises the various treatments tried and found wanting in MND but there are a number of promising strategies that might yield treatments to influence the course of the disease.

\section{TRIALS IN PROGRESS}

\section{Branched chain amino acids}

Plaitakis $e t a \bar{l}^{0}$ reported significant benefit in maintenance of muscle strength and walking ability in 22 patients with MND treated with branched chain amino acids (L-leucine/Lisoleucine/L-valine). This trial was based on the hypothesis that partial glutamate dehydrogenase deficiency can occur in atypical MND and forms of multiple system atrophy. Branched chain amino acids activate gluta-
Table 5 Various therapeutic trials undertaken or in progress in motor neuron disease

\begin{tabular}{l} 
Immunotherapy: \\
Steroids \\
Immunosuppression \\
Whole body lymphoid irradiation \\
Plasma exchange \\
Interferon \\
Vitamin and anti-free radical therapy: \\
Vitamin E \\
Vitamin B12 \\
Selegiline \\
N-acetylcysteine \\
Miscellaneous: \\
Chelating agents \\
Thyrotrophin releasing hormone \\
Levodopa \\
Amantadine \\
Guanidine \\
Naloxone \\
Cytosine arabinoside \\
Bovine gangliosides \\
Testosterone \\
Pancreatic extracts \\
Agents thought to modulate glutaminergic transmission: \\
Dextromethorphan \\
Lamotrigine \\
Branched chain amino acids \\
Riluzole \\
Current trials: \\
Riluzole \\
N-acetylcysteine \\
Branched chain amino acids \\
Motor neuron neurotrophic factors: \\
(a) Ciliary neurotrophic factor \\
(b) Insulin-like growth factor 1 \\
(c) Brain-derived neurotrophic factor \\
\hline
\end{tabular}

mate dehydrogenase and may modify glutamate metabolism and glutaminergic transmission. A double blind, placebo controlled trial involving 126 patients found a higher mortality in the group randomised to active treatment, but patients in this group were slightly older than the placebo group, and had a lower forced vital capacity. ${ }^{51} \mathrm{~A}$ multicentre, double blind, placebo controlled trial of branched chain amino acids involving over 400 patients has now been completed in Europe and the results are awaited.

\section{Glutamate inhibition}

Inhibition of glutamate has been tried with dextromethorphan, lamotrigine, MK-801, and, more recently, riluzole. ${ }^{52}$ Riluzole modulates glutaminergic transmissions by presynaptic inhibition of glutamate release and postsynaptic interference with the effects of excitatory amino acids. Riluzole may also act by blocking voltage dependent sodium channels and the guanylate cyclase linked second messenger system..$^{53}$ Bensimon et $a{ }^{51}$ reported the results of a prospective, randomised, double blind, placebo controlled trial of riluzole in 155 patients with definite or probable MND. The primary endpoints were survival and rates of change of functional status and, at the end of one year, survival was significantly prolonged in the riluzole group (74\%) compared with the placebo group $(58 \%)$. The apparent effect of riluzole was greater in patients with bulbar onset compared with limb onset MND. In those with bulbar onset, the survival rate of 12 months was $73 \%$ with riluzole compared with $35 \%$ with placebo $(p=0.014)$, whereas in the patients with limb onset the difference was not significant. Decline in muscle strength was significantly slower in the riluzole group 
as a whole compared with placebo. Although randomisation was stratified according to the site of onset of the disease (bulbar $v$ limb onset, by first symptoms), the numbers in the bulbar onset group were small $(32 ; 17$ placebo and 15 riluzole), and there were minor advantages for the riluzole group in terms of age and bulbar function scores, although these differences were not statistically significant. Twenty four of the 155 patients randomised did not meet all the entry criteria, but nonetheless all were considered to have ALS and were included in the analysis. Withdrawals due to adverse drug reactions were more common in the riluzole than the placebo group. These results cannot be taken as proof of the efficacy of riluzole, and it is not clear why patients with bulbar onset should respond better than those with limb onset-although such patients might receive the drug earlier in the course of lower motor neuron degeneration. On the other hand, ventilatory function was worse in these subjects than in those with limb onset disease. Only a larger trial can answer these questions, and a multicentre trial of riluzole in Europe and North America is now underway and has recruited over 950 patients.

\section{$N$-Acetylcysteine}

$\mathrm{N}$-Acetylcysteine (NAC) is a free radical scavenger and is a direct and indirect precursor of glutathione, a major intracellular oxidant defence system. Louwerse et $a b^{55}$ reported the results of a randomised, double blind, placebo controlled trial in 110 patients with MND. ${ }^{55}$ After one year, the treated group showed a $29 \%$ (non-significant) reduction in mortality in MND of spinal onset but not of bulbar onset.

\section{Neurotrophic factors}

Ciliary neurotrophic factor is a neuroactive cytokine made in Schwann cells of peripheral nerves which initiates repair processes. It promotes survival of rat and human motor neurons in tissue culture, promotes sprouting of motor axon terminals, and slows progression in murine models of motor neuron degeneration. ${ }^{56}$ Recombinant human ciliary neurotrophic factor is being tested in subjects with MND. Systemic side effects due to the cytokine-like actions of the factor are likely to be problematic. ${ }^{57}$

Insulin-like growth factor is a 70 amino acid polypeptide which mediates the action of growth hormone. It enhances motor neuron sprouting in vivo and increases muscle endplate size in rats. ${ }^{5859}$ Multicentre trials are now underway.

Brain derived neurotrophic factor enhances the survival of motor neurons following axotomy and can rescue motor neurons from death during development. ${ }^{6061}$ Trials of recombinant human factor have started in North America.

FUTURE PROSPECTS

Although multifocal motor neuropathies may respond to immunosuppressive treatment, including intravenous infusion of immune globulin, ${ }^{62}$ aggressive immunomodulation does not improve MND proper. ${ }^{63}$ If antibodies against calcium channels ${ }^{64}{ }^{65}$ are found to play a part in pathogenesis, there may be further attempts to treat MND as an autoimmune disorder, but present indications are that this approach has failed. Future strategies for neuroprotection in MND are likely to focus on new glutamate antagonists, agents protecting against free radical damage, neurotrophic factors, and on combinations of these.

A major difficulty with the human recombinant neurotrophic factors is that they have to be administered by subcutaneous, intravenous or even intrathecal routes, and access to the brain and spinal cord is limited. Thus research is likely to focus on signal transduction mechanisms to identify compounds that activate intracellular systems that respond to neurotrophic factors.

\section{SUPPORTIVE TREATMENT AND TREATMENT OF} COMPLICATIONS

Dysarthria and communication problems

Dysarthria occurs in most patients before death. ${ }^{66}$ In a hospice setting, only $25 \%$ had normal speech on admission. ${ }^{67}{ }^{68}$ Early referral to a speech therapist and access to a communication aids centre are important. Management measures include encouraging the patient to decrease the speed of speech. Application of local ice, or use of baclofen, may help to reduce tongue spasticity. Other measures include a palatal loop or palatal lift (for hypernasality caused by nasal escape of air). For patients with anarthria, communication aids may be useful. These include computerised type-in speech devices (Canon Communicator), and Lightwriters or Memowriter (equipped with memory). In cases of severe physical impairment, scanning aids such as the Possum Communicator, in which a switch operated cursor light or pointer identifies each item, letter or symbol, can be invaluable.

\section{Salivation}

Drooling or salivary dribbling is often a problem in people with severe bulbar symptoms. Two to three litres of saliva are produced and swallowed each day normally. ${ }^{69}$ Loss of automatic swallowing and of erect head posture cause drooling of saliva and persistent dribbling is a major source of distress to patients. Family and friends should be aware that dribbling is not a sign of mental impairment. Helpful interventions include neck support and correction of the head position; treatment of mouth infections (usually fungal); and application of local ice in the mouth. The lip seal may be strengthened by simple lip exercises (closing lips against finger resistance). Anticholinergic drugs, including atropine or more usually hyoscine hydrobromide elixir or skin patches, may prove effec- 
tive. Amitriptyline is sometimes helpful, and has the added benefit of improving sleep and mood. Portable suction devices are available, as well as cosmetic assistance to trigger automatic swallowing. Surgical measures may be beneficial, such as transtympanic neurectomy (section of chorda tympani in the middle ear), ${ }^{70}$ and salivary irradiation or denervation.

\section{Swallowing}

Dysphagia is a major problem in $50-70 \%$ of patients with MND, and may lead to choking, dehydration, weight loss, salivary dribbling, and aspiration pneumonia. ${ }^{71}$ Investigation of dysphagia in MND may include cine-videofluoroscopy, which involves swallowing a barium suspension of varying consistency, and analysis of the various stages of swallowing. Patients should be encouraged to eat where they feel relaxed and comfortable, as slowness of eating and dribbling may cause severe social embarrassment. It may be possible to improve head posture and head support, as well as lip closure. Again, application of ice in the mouth may reduce spasticity of the tongue. Dietary measures may include avoidance of food and drink which precipitate coughing and choking, such as highly spiced foods or spirits. Dairy foods (milk and cream) or proprietary thickeners may increase volume and tenacity of mouth secretions. ${ }^{66}$ If the automatic swallow reflex becomes depressed in $\mathrm{MND}$, it may be triggered by chewing sweets or gum.

Some drugs may help with swallowing problems: baclofen reduces spasticity and is sometimes helpful in doses up to $80-90 \mathrm{mg}$. L-threonine may help. Anticholinesterase drugs, however, are usually unhelpful, and increase salivation. Division of the fibres of the cricopharyngeus muscle may help in cases of cricopharyngeal spasm due to demonstrable pseudobulbar incoordination. Postoperative mortality appears to be high $(6 \%$ $30 \%)$ in some published series and this procedure is not widely practised. Nasogastric feeding may be useful for temporary feeding when dysphagia is made worse by oral or upper respiratory tract infection.

The definitive procedure is percutaneous endoscopic gastrostomy (PEG). PEG is helpful in patients with advanced dysphagia, and involves the placement of a small bore catheter inserted under local anaesthesia. ${ }^{71} 72$ It is helpful to broach the idea relatively early in the course of the disease in people with bulbar onset. PEG requires careful dietetic advice on caloric and nutritional intake and food selection. Indications for PEG include severe dehydration, frequent choking, aspiration pneumonia, progressive weight loss, and exhaustion due to laboured feeding. PEG is particularly helpful in patients with severe bulbar symptoms but with relatively good limb function. It relieves the burden of laboured attempts to take adequate nourishment and often improves wellbeing and quality of life, at least for some months. The option of PEG should be discussed with patients and carers early rather than late in the disease. For patients who refuse PEG, but who can swallow some fluids, oral morphine elixir given four hourly or 12 hourly as a slow release preparation relieves hunger and thirst to some extent, and may avoid the need for a nasogastric tube.

Choking, principally with fluids, accompanies dysphagia and patients are often anxious that they will choke to death. In fact, this rarely happens. ${ }^{6768} \mathrm{~A}$ home suction device may be helpful, at least to provide reassurance. Postural advice-for example, asking patients to lean forward, can be offered, and it may be necessary to teach carers the Heimlich manoeuvre, so that foreign bodies may be dislodged in case of obstruction.

\section{Ventilatory failure}

Most patients with MND die of ventilatory failure, usually complicated by varying degrees of aspiration pneumonia. Weakness of the diaphragm may be an early feature of the disease, and orthopnea is a common symptom..$^{73}$ Respiratory insufficiency is best monitored by measuring forced vital capacity, specifically measurements taken while sitting and supine (it usually drops to less than $20 \%$ ). Other measures that may help include respiratory rate; cough strength, and diaphragmatic excursion; and ability to count up to 20 in one breath. Chest radiograph is important when ventilatory function deteriorates suddenly, as these patients are at risk for pulmonary embolism and infection. Arterial blood gases are maintained normal or near normal until a very late stage in many patients. Nocturnal oximetry may prove helpful in evaluating the need for assisted ventilation during sleep, but the main indication for assisted ventilation is respiratory insufficiency with disabling symptoms associated with nocturnal hypercapnia.

The management of respiratory failure includes regular monitoring of forced vital capacity with spirometry, correct positioning, particularly during sleep; frequent turning at night; and prevention of aspiration and removal of secretions with a hand operated or electrical suction machine. Prompt treatment of bronchitis or pneumonia may forestall ventilatory failure. Shortness of breath can sometimes be helped by use of a continuous positive airway pressure device along with a humidifier. Some patients benefit from a cuirass with negative pressure ventilation. ${ }^{73}$ Intermittent positive pressure ventilation may enable patients to sleep, but requires tracheotomy, and should, in our view, be considered only after full discussion with family. Nevertheless, it may be appropriate for some patients. ${ }^{745}$ Tracheostomy is undertaken more frequently in North America and parts of continental Europe than in the United Kingdom. It is often used as a temporary measure to tide people over an infection, but without intermittent positive pressure ventilation, death almost always follows within a few weeks. In northern Illinois, only $8.6 \%$ of MND patients chose home ventilation. ${ }^{75}$ Home ventilation is expensive and imposes 
significant burdens on families. Oral morphine often controls dyspnoea effectively and can be titrated to avoid drowsiness; it does not necessarily shorten life and can significantly reduce distress.

\section{Spasticity}

This may be helped by the use of benzodiazepines, baclofen, or dantrolene. Severe contractures may be helped by surgical lengthening or division of soft tissues. This can be performed under local or spinal anaesthesia.

Pain

Pain may occur in $45-64 \%$ patients with MND and arises from muscle cramps, stiff joints, spasticity, abdominal colic due to constipation, and skin pressure. ${ }^{6876}$ Pain may be controlled by correct positioning of the patient and use of a turning bed at night; physiotherapy (changing position, etc.); and drugs, including muscle relaxants (benzodiazepines or baclofen), non-steroidal antiinflammatory drugs, and opioids (in advanced stages of the disease).

\section{Constipation}

Constipation may occur due to weakness of pelvic muscles, improper diet, spasticity, and drugs such as anticholinergics and opioids. Management options include increase of dietary fibre and maintenance of fluid intake; bulk-forming laxatives such as methyl cellulose, and osmotic laxatives such as lactulose; and suppositories and enemas.

Peripheral oedema

Dependent pedal oedema occurs in virtually all patients with MND. This can be counteracted by elevation of legs, elastic stockings, and cautious use of diuretics.

\section{Sleep disturbances}

Disturbed sleep and poor nights may occur due to pain, depression and anxiety, immobility and sleep apnoea. A suitable bed is of utmost importance to make the nights more comfortable for patients. Beds should be of correct height with a firm mattress, and turning beds with powered elevator are an added advantage.

\section{Emotional problems}

These include depression and anxiety. These problems can be partially helped by effective management of the other disabilities described above, and by antidepressant drugs in selected cases. Emotional lability may respond to imipramine.

\section{FINAL STAGES}

Severe physical disability may require the use of an electronic scanning device whereby each item, letter, or symbol is identified by a switch operated cursor or pointer. The Possum Communicator is such a device, and environmental control devices operated by the same method are available. Sophisticated communication aids are available, and with this and support from home care teams, many people with MND can remain at home until death. In the United Kingdom, support from a local hospice is often the key factor that allows this to happen.

Patients with MND usually die from respiratory failure, inhalation and aspiration pneumonia, or other infections. Pulmonary embolism is not uncommon. The various strategies available to manage these problems have already been discussed. In the last stage it is important to maintain symptomatic relief and avoid distress to patient and family as far as practicable. Narcotic analgesics (morphine or diamorphine) are useful, and may be given as a suppository, intramuscular or subcutaneous injection, or by continuous subcutaneous infusion.

The consultant and general practitioner should be available for consultation, and the keyworker should stay in close contact with the family. Hospital or hospice admission should be offered if appropriate, to ensure the stress-free death of the patient whenever possible.

Following the death of the patient, a letter of condolence should be sent to the partner or family, and the spouse should be offered counselling if necessary.

\section{Audit issues}

Provision for MND support services have not been adequately audited in the past. The Royal College of Physicians held a consensus conference on the management of chronic neurological disorders in 1990, and identified a number of areas in the management of MND which can be audited. These include accessibility to specialist care (with information regarding waiting list period and travelling distance for neurological consultation) and multidisciplinary care (counselling, community physiotherapy, speech therapists, day hospitals, and provision of aids).

Provision should be made for continuing care (outpatient visit when the patient is seen by the consultant), and for full information and liaison (information given to patients about the MND Association, consultations to explain properly the diagnosis and its implications, liaison between the hospital neurology team and the general practitioner). The role of the keyworker should be defined. Other areas of patient care which can be audited include management of symptoms such as pain, dysphagia, salivary drooling, and insomnia; patient satisfaction with multidisciplinary care and general practitioner; support services for specialist help with problems such as dysphagia and availability of PEG; and provision for management of respiratory failure, including assisted ventilation. The figure shows a scheme used for audit of the MND care team of the MND Care and Research Centre at the Maudsley and King's College Hospitals, London. 


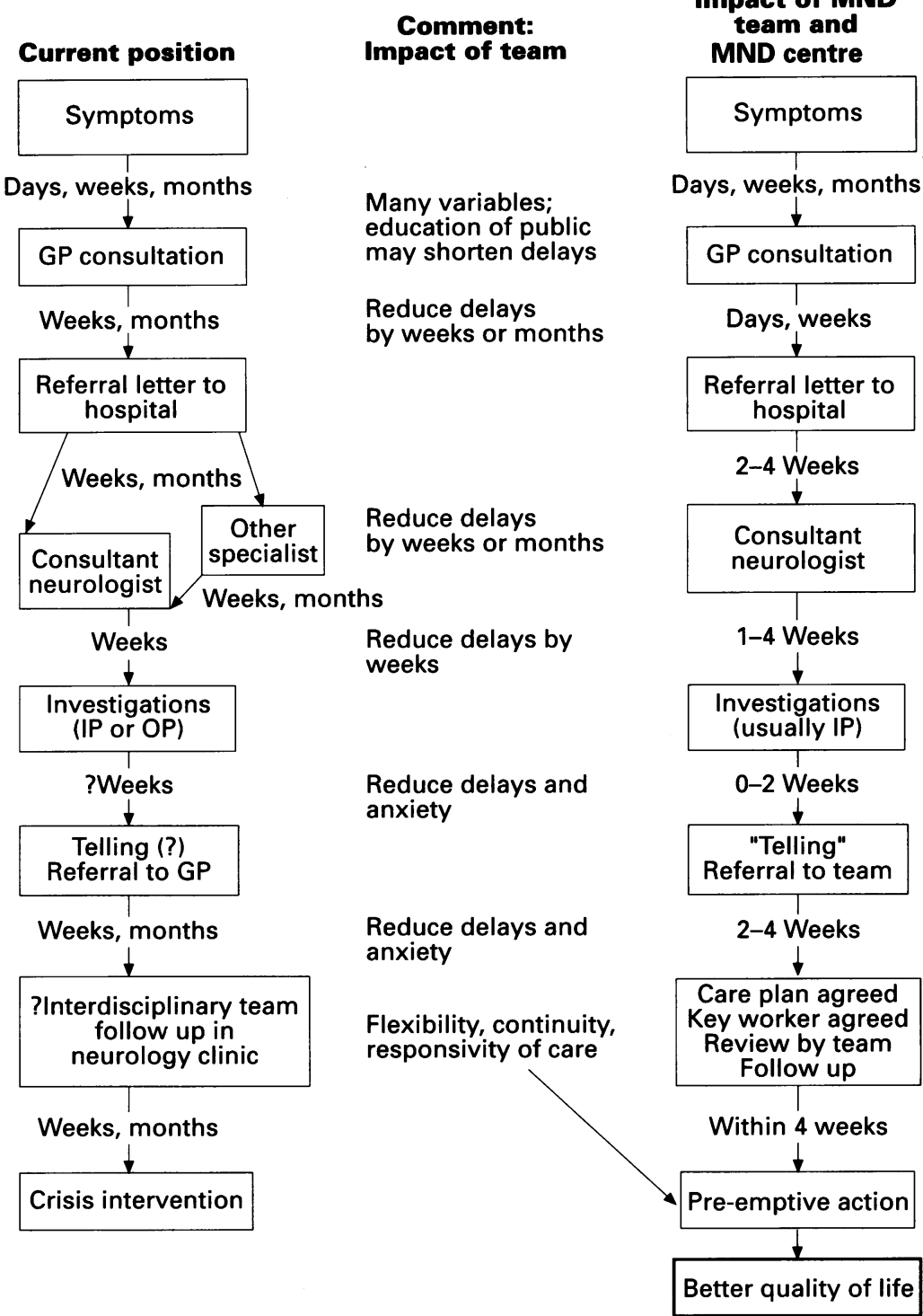

Motor neuron disease: a patient's perspective (suggested framework for audit).

1 Mulder DW, Kurland LT, Offord KP, Beard CM Familial adult motor neuron disease: Amyotrophic Familial adult motor neuron disease:

2 Veltema AN, Roos RAC, Bruyn GW. Autosomal dominant adult amyotrophic lateral sclerosis. $₹$ Neurol $S c i$ 1990:97:93-115.

3 Hirano A, Kurland LT, Krooth RS, Lessel S Parkinsonism-dementia complex, an endemic disease on the island of Guam. Brain 1961;84:642-61.

4 Pringle CE, Hudson AJ, Munoz DG, Kiernan JA, Brown WF, Ebers GC. Primary lateral sclerosis. Clinical features, neuropathology and diagnostic criteria. Brain 1992;115:495-520.

5 Swash M, Leigh PN. Criteria for diagnosis of familial amyotrophic lateral sclerosis. Neuromusc Disord 1992;2: 7-9.

6 Gaffney JS, Sufit RL, Hartmann H, et al. Clinical diagnosis of amyotrophic lateral sclerosis (ALS): a clinicopathological study of 'El Escorial' Working Group criteria in 36 autopsied patients [abstract]. Neurology criteria in 36 a

7 Hudson AJ. Amyotrophic lateral sclerosis and it's association with dementia, parkinsonism and other neurological disorders: A review. Brain 1981;104:217-47.

8 Kew JJM, Leigh PN. Dementia with motor neuron disease. In: Rossor MN, ed. Baillière's clinical neurology: unusual dementias, Vol. 1 (3). London: Baillière Tindall 1992:611-26.

9 Neary D, Snowden JS, Mann DMA, Northern B, Boulding PJ, MacDermott N. Frontal lobe dementia and motor neuron disease. $\mathcal{F}$ Neurol Neurosurg Psychiatry 1990;53:23-32.

10 La Spada AR, Wilson EM, Lubahn DE, Harding AE Fischbeck KH. Androgen receptor gene mutations in Xlinked spinal and bulbar muscular atrophy. Nature 1991;352:77-9.

11 Rosen DR, Siddique T, Patterson D, et al. Mutations in $\mathrm{Cu} / \mathrm{Zn}$ superoxide dismutase gene are associated with familial amyotrophic lateral sclerosis. Nature 1993;362:59-62.

12 De Jong JMP. The World Federation of Neurology classification of spinal muscular atrophies and other disorders of the motor neurons. In: Vinken PJ, Bruyn GW, Klawans HL, eds. Handbook of clinical neurology, Vol.15(9), Diseases of the motor system. Amsterdam: Elsevier Science Publishers, 1991:1-12.

13 Jokelainen M. Amyotrophic lateral sclerosis in Finland. 2. Clinical characteristics. Acta Neurol Scand 1977;56: 194-204.

$14 \mathrm{Li} \mathrm{T}-\mathrm{M}$, Alberman E, Swash M. Clinical associations of 560 cases of motor neuron disease. $\mathcal{F}$ Neurol Neurosurg Psychiatry 1990;53:1043-5.

15 Norris F, Shepherd R, Denys E, et al. Onset, natural history and outcome in idiopathic motor neuron disease. $\mathcal{F}$ Neurol Sci 1993;118:48-55.

16 Jamal GA, Weir AI, Hansen S, Ballantyne JP. Sensory involvement in motor neuron disease: further evidence involvement in motor neuron disease: further evidence Neurol Neurosurg Psychiatry 1985;48:906-10.

17 Bradley WG. Recent views on amyotrophic lateral sclerosis with emphasis on electrophysiological studies. Muscle Nerve 1987;10:490-502.

18 Swash M, Scholtz CL, Vowles GH, Ingram DA. Selective asymmetrical vulnerability of corticospinal and spinocerebellar tracts in motor neuron disease. $f$ Neurol Neurosurg Psychiatry 1988;51:785-9.

19 Kew JJM, Goldstein LH, Leigh PN, et al. The relationship between abnormalities of cognitive function and cerebral activation in amyotrophic lateral sclerosis. Brain 1993;116:1399-424.

20 Gunnarsson L-G, Dahlborn K, Strandman E. Motor neuron disease and dementia reported among 13 members of a single family. Acta Neurol Scand 1991;84:429-33.

21 Rodgers-Johnson P, Garruto RM, Yanagihara R, Chen KM, Gajdusek DC, Gibbs CJ. Amyotrophic lateral sclerosis and parkinsonism-dementia on Guam: a 30 year evaluation and neuropathologic trends. Neurology 1986; 36:7-13

22 Harding AE, Thomas PK, Baraitser M, Bradbury PC, Morgan-Hughes JA, Poneford JR. X-linked recessive bulbospinal neuronopathy: a report of ten cases. $\mathcal{F}$ Neurol Neurosurg Psychiatry 1982;45:1012-9.

23 Lambert EH, Mulder DW. Electromyographic studies in amyotrophic lateral sclerosis. Mayo Clinic Proc 1957;32: $441-6$.

24 Behnia M, Kelly JJ. Role of electromyography in amyotrophic lateral sclerosis. Muscle Nerve 1991;14: t236-341.

25 Kelly J, Thibodeau L, Andres PL, Finison LJ. Use of electrophysiologic tests to measure disease progression electrophysiologic tests to measure disease progression

26 Friedman DP, Tartaglino LM. Amyotrophic lateral sclerosis: hyperintensity of the corticospinal tracts on MR images of the spinal cord. AfR 1993;160:604-6.

27 Goodin DS, Rowley HA, Olney RK. Magnetic resonance imaging in amyotrophic lateral sclerosis. Ann Neurol 1988;23:418-20.

28 Oba H, Araki T, Ohtomo K, et al. Amyotrophic lateral sclerosis: T2 shortening in motor cortex at MR imaging. Radiology 1993;189:843-6.

29 Younger DS, Rowland LP, Latov N, et al. Lymphoma, motor neuron diseases, and amyotrophic lateral sclerosis. Ann Neurol 1991;29:78-86.

30 Sadiq SA, Thomas FP, Kilidirias K, et al. The spectrum of neurological disease associated with anti-GM1 antibodies. Neurology 1990;40:1067-92.

31 Pestronk A. Invited review: motor neuropathies, motor neuron disorders and anti-glycolipid antibodies. Muscle Nerve 1991;14:927-36.

32 Szabo A, Dalmau J, Manly G, et al. HuD, a paraneoplastic encephalomyelitis antigen, contains RNA-binding domains and is homologous to Elav and Sex-lethal. Cell 1991;67:325-33.

33 Leigh PN. Amyotrophic lateral sclerosis and other motor neuron disorders. Curr Opin Neurol Neurosurg 1991;4: 586-96.

34 Kurtzke JF. Risk factors in amyotrophic lateral sclerosis. In: Rowland LP, ed. Amyotrophic lateral sclerosis and other motor neuron diseases. Advances in neurology, Vol. 56, New York: Raven Press, 1991:245-70.

35 Lilienfield DE, Chan E, Ehland J, et al. Rising mortality from motor neuron disease in the USA, 1962-1984. Lancet 1989;i:710-3.

36 Chancellor AM, Warlow CP. Adult onset motor neuron disease: worldwide mortality, incidence and distribution disease: worldwide mortality, incidence and distribution
since 1950. $\not$ Neurol Neurosurg Psychiatry 1992;55: since 1950

37 Neilson S, Robinson I, Rose FC, Hunter M. Rising mortality from motor neuron disease: an explanation. Acta Neurol Scand 1993;87:184-91.

38 Sienko DG, Davis JP, Taylor JA, Brooks BR. Amyotrophic lateral sclerosis. A case-control study following detection of a cluster in a small Wisconsin community. Arch Neurol 1990;47:38-41.

39 Swingler RJ, Fraser H, Warlow CP. Motor neuron disease and polio in Scotland. $\mathcal{F}$ Neurol Neurosurg Psychiatry 1992;55:1116-20.

40 Spencer PS, Nunn PB, Hugon J, et al. Linkage of Guam amyotrophic lateral sclerosis-parkinsonism-dementia to a plant excitotoxin. Science 1987;237:517-22.

41 Duncan MW, Steel JC, Kopin IJ, Markey SP. 2-amino-3(methylamino)-propanoic acid (BMAA) in cycad flour: An unlikely cause of amyotrophic lateral sclerosis and 
parkinsonism-dementia of Guam. Neurology 1990;40: 767-72.

42 Elian $M$, Dean $G$. The changing pattern of motor neuron disease and multiple sclerosis in England and Wales and the Republic of Ireland. Neuroepidemiology 1992;11: $236-43$

43 Dean G, Elian M. Motor neuron disease and multiple sclerosis mortality in Australia, New Zealand and South Africa compared with England and Wales. $\mathcal{f}$ Neurol Neurosurg Psychiatry 1993;56:633-7.

44 Olivares L, San Esteban E, Alter M. Mexican "resistance" to amyotrophic lateral sclerosis. Arch Neurol 1972;27: 397-402.

45 Caroscio JT, Calhoun WF, Yahr MD. Prognostic factors in motor neuron disease: a prospective study of longevity. In: FC Rose, ed. Research progress in motor neuron disease, London: Pitman Books, 1984:34-43.

46 Chancellor AM, Slattery JM, Fraser H, Swingler RJ, Holloway SM, Warlow CP. The prognosis of adult Holloway SM, Warlow CP. The prognosis of adult
onset motor neuron disease: a prospective study based onset motor neuron disease: a prospective study based
on the Scottish motor neuron disease register. $\mathscr{f}$ Neurol on the Scottish motor

47 Mulder DW, Howard FM. Patient resistance and prognosis in amyotrophic lateral sclerosis. Mayo Clin Proc 1976;51:532-41.

48 Tucker T, Layzer RB, Miller RG, Chad D. Subacute reversible motor neuron disease. Neurology 1991;41: 1541-4.

49 Hogg KE, Goldstein LH, Leigh PN. The psychological impact of motor neuron disease. Psychol Med 1994: (in press).

50 Plaitakis A, Berl S, Yahr MD. Abnormal glutamate metabolism in adult-onset neurological disorder. Science 1982;215:193-6.

51 The Italian ALS Study Group. Branched-chain amino acids and amyotrophic lateral sclerosis: A treatment acids and amyotrophic lateral scle
failure? Neurology 1993;53:2466-70.

52 Bensimon G, Lacomblez V, Mèininger $V$ and the ALS/Riluzole study group. A controlled trial of riluzole in amyotrophic lateral sclerosis. $N$ Engl f Med 1994; 330:585-91.

53 Benoit E, Escande D. Riluzole specifically blocks inactivated $\mathrm{Na}$ channels in myelinated nerve fibre. Pflügers Arch 1991;419:603-9.

54 Doble A, Hubert JP, Blanchard JC. Pertussis toxin pretreatment abolishes the inhibitory effect of riluzole and carbachol on $\mathrm{D}-\left[{ }^{3} \mathrm{H}\right]$ aspartate release from cultured

55 Louwerse ES, Weverling GJ, Tijssen J-GP, Meyjes FEP, de Jong JMBV. The efficacy of $\mathrm{N}$-acetylcysteine in amyotrophic lateral sclerosis. Fourth International Symposium on $A L S / M N D$, Neuroprotection and Clinical Symposium on $A L S / M N D, N$
Trials. Paris, 1993 [abstract].

56 Dittrich F, Thoenen H, Sendtner M. Ciliary neurotrophic factor: pharmacokinetics and acute phase response in rat. Ann Neurol 1994;35:151-63.

57 Rowland LP. Amyotrophic lateral sclerosis: Theories and therapies. Ann Neurol 1994;35:129-30.
58 Caroni P, Grandes P. Nerve sprouting in innervated adult skeletal muscle induced by exposure to elevated levels of insulin-like growth factors. F Cell Biol 1990;110: 1307-17.

59 Yu E, Callison KV, Roberts-Lewis JM, Grebow P. The effect of insulin-like growth factor-1 on the neuromuscular junction in adult rat skeletal muscle. Soc Neurosci Abstr 1991;17:225A [abstract].

60 Yan Q, Elliott J, Snider WD. Brain-derived neurotrophic factor rescues spinal motor neurons from axotomyinduced cell death. Nature 1992;360:753-5.

61 Oppenheim RW, Qin-Wei Y, Prevette D, Yan Q. Brainderived neurotrophic factor rescues developing avian motoneurons from cell death. Nature 1992;360:755-7.

62 Chaudhry V, Corse AM, Cornblath DR, et al. Multifocal motor neuropathy: response to human immune globumotor neuropathy: response to
lin. Ann Neurol 1993;33:237-42.

63 Drachman DB, Chaudhry V, Cornblath D, et al. Trial of immunosuppression in amyotrophic lateral sclerosis immunosuppression in amyotrophic lateral sclerosis using total

64 Glenn Smith R, Hamilton S, Hofmann F, et al. Serum antibodies to $L$-type calcium channels in patients with amyotrophic lateral sclerosis. $N$ Engl f Med 1992;327: 1721-8.

65 Kimura F, Smith RG, Delbono O, et al. Amyotrophic lateral sclerosis patient antibodies label $\mathrm{Ca}^{2+}$ channel $\alpha_{1}$ subunit. Ann Neurol 1994;35:164-71.

66 Enderby PM, Langton-Hewer R. Management of motor neuron disease. Edinburgh: Churchill Livingstone, 1987: $22-47$.

67 Saunders CM, Walsh TD, Smith M (1981). Hospice care in motor neuron disease. In: Saunders CM, ed. Hospice: the living idea. London: Edward Arnold, 126-155.

68 O'Brien T, Kelly M, Saunders C. Motor neuron disease: a hospice perspective. BMF 1992;304:471-3.

69 Crossner CG. Salivary flow rate in children and adolescents. Swed Dent 7 1984;8:271-6.

$70 \mathrm{Zalin} \mathrm{H}$, Cooney TC. Chorda tympani neurectomy-a new approach to submandibular salivary obstruction. $\mathrm{Br}$ f Surg 1974;61:391-4.

71 Langton Hewer R, Enderby PM. Bulbar dysfunction. In: Clifford, F, Rose F, ed. Amyotrophic lateral sclerosis, Vol. 1. New York: Demos, 1990:99-107.

72 Norris FH, Smith RA, Denys EH. Motor neuron disease: towards better care. BMF 1985;291:259-62.

73 Howard RS, Wiles GM, Loh L. Respiratory complications and their management in motor neuron disease. Brain 1989;112:1155-70.

74 Norris FH, Fallat RJ. Respiratory function. In: Williams AC, ed. Motor neuron disease: London: Chapman \& AC, ed. Motor newro

75 Moss AH, Casey P, Stocking CB, Roos RP, Brooks BR, Siegler $M$. Home ventilation for amyotrophic lateral Siegler $M$. Home ventilation for amyotrophic lateral
sclerosis patients: Outcomes, costs, and patient, family sclerosis patients: Outcomes, costs, and patient, family
and physician attitudes. Neurology 1993;43:438-43.

76 Newrick PG, Langton Hewer R. Pain in motor neuron disease. F Neurol Neurosurg Psychiatry 1985;48:838-40. 